\title{
Can virtual touch tissue imaging quantification be a reliable method to detect anterior talofibular ligament type I injury at the acute, subacute, and chronic stages?
}

\author{
Xiu Chen ${ }^{1}$, Liang Wang ${ }^{1}$, Xiuyun $\mathrm{Li}^{1}$, Pinguo Fu ${ }^{2}$, Maosheng $\mathrm{Xu}^{1}$, Chunpeng Zou ${ }^{1}$, Xingwang $\mathrm{Li}^{2 \#}$, \\ Yanyan Dong ${ }^{1 \#}$
}

${ }^{1}$ Department of Ultrasonic Diagnosis, The Second Affiliated Hospital and Yuying Children's Hospital of Wenzhou Medical University, Wenzhou, China; ${ }^{2}$ Department of Anesthesiology and Perioperative Medicine, The Second Affiliated Hospital and Yuying Children's Hospital of Wenzhou Medical University, Wenzhou, China

Contributions: (I) Conception and design: X Chen, X Li, Y Dong; (II) Administrative support: C Zou, X Li; (III) Provision of study materials or patients: X Chen, L Wang, X Li, C Zou, Y Dong; (IV) Collection and assembly of data: X Chen, L Wang, X Li, P Fu, M Xu; (V) Data analysis and interpretation: All authors; (VI) Manuscript writing: All authors; (VII) Final approval of manuscript: All authors.

\#These authors contributed equally to this work.

Correspondence to: Xingwang Li. Department of Anesthesiology and Perioperative Medicine, The Second Affiliated Hospital and Yuying Children's Hospital of Wenzhou Medical University, No. 109, Xueyuan West Road, Wenzhou 325000, China. Email: li-xingwang@163.com; Yanyan Dong. Department of Ultrasonic Diagnosis, The Second Affiliated Hospital and Yuying Children's Hospital of Wenzhou Medical University, No. 109, Xueyuan West Road, Wenzhou 325000, China. Email: yan217168@wzhealth.com.

Background: Anterior talofibular ligament (ATFL) injury affects ankle joint stability. To date, very few studies have examined tissue stiffness changes inside injured ligaments. Virtual touch tissue imaging quantification (VTIQ) allows for the non-invasive quantitative measurement of tissue stiffness. The present study aimed to examine the efficacy of VTIQ as a method for detecting ligament injury.

Methods: A total of 206 patients diagnosed with unilateral ATFL type I injury (81 acute cases, 69 subacute cases, and 56 chronic cases) were reviewed retrospectively. Shear wave velocity (SWV) values were collected from both the injured and non-affected sides of the ATFL using a virtual touch tissue imaging quantification technique (ACUSON Oxana 2, Siemens Medical Solutions USA, Inc.).

Results: The average SWV of injured ATFL was $4.09 \pm 1.15 \mathrm{~m} / \mathrm{s}$ in the acute group, $5.60 \pm 1.39 \mathrm{~m} / \mathrm{s}$ in the subacute group, and $7.74 \pm 1.44 \mathrm{~m} / \mathrm{s}$ in the chronic group $(\mathrm{P}<0.001)$. The $\mathrm{SWV}$ values of the ATFL on the nonaffected side were almost identical (acute $7.50 \pm 1.12 \mathrm{~m} / \mathrm{s}$, subacute $7.53 \pm 1.06 \mathrm{~m} / \mathrm{s}$, and chronic $7.61 \pm 1.30 \mathrm{~m} / \mathrm{s}$; $\mathrm{P}>0.05)$. The injured ATFL had a significantly lower SWV value than the non-affected ATFL in the acute and subacute groups $(\mathrm{P}<0.001)$; however, there was no significant difference in the chronic group $(\mathrm{P}>0.05)$. Concerning the validity of SWV as a predictor of acute and subacute ATFL injury, the receiver operator characteristics curve analysis showed that the best cut-off point for SWV was $6.165 \mathrm{~m} / \mathrm{s}$, with $84.3 \%$ sensitivity, 88.5\% specificity, and an area under the curve of 0.93 (95\% CI, 0.90-0.95).

Conclusions: VTIQ is a reliable sonographic method for detecting acute and subacute ATFL type I injury.

Keywords: Ankle injury; lateral ligament; ankle; elasticity imaging technique

Submitted Feb 19, 2021. Accepted for publication May 06, 2021.

doi: 10.21037/qims-21-203

View this article at: http://dx.doi.org/10.21037/qims-21-203 


\section{Introduction}

As one of the most important joints in the human body, the ankle joint is responsible for supporting body weight and maintaining the motion stability of the foot-shank complex. However, when an ankle sprain occurs, the above joint properties can be strongly affected by structural damage, such as ligament injuries. An ankle sprain is a very common injury (1-3) and often involves the periarticular ligaments, including the anterior talofibular ligament (ATFL), which is one of the most vulnerable ligaments (4). However, ATFL injuries are often unrecognized and underrated (5). ATFL injuries can be classified into the following 3 types (6): type I, ligament presents with an interstitial tear, without macroscopic disruption; type II, partial tear; and type III, complete tear. Due to its mild clinical symptoms, type I is the most neglected injury. An injured ATFL may increase ligament laxity $(7,8)$, which has a close relationship with recurrent ankle sprains and chronic ankle instability (CAI) (9-11). The latter can lead to more troublesome complications, such as post-traumatic osteoarthritis (12), and adversely affect patients' quality of life. Thus, researchers need to investigate specific tissue changes within injured ATFLs and attempt to identify which of these changes are related to ligament laxity.

To date, the vast majority of studies have focused on ATFL morphological changes (13-16), including changes to ligament thickness, length, width, continuity, and crosssectional area. Several studies have explored the possible correlation between ATFL structural changes and ankle joint stability. Some investigators (14) have found that injured ATFLs were longer and thicker than healthy ATFLs. Other researchers (16) have shown that chronic ankle sprain patients have a significantly greater ATFL area than control subjects. However, to date, there has been little research on ligament stiffness.

Virtual touch tissue imaging quantification (VTIQ) is a non-invasive ultrasonic palpation method used to take quantitative measurements of tissue stiffness. For decades, VTIQ has been well established in the diagnostics of several fine structures, such as the skin $(17)$, tendons $(18,19)$, and nerves (20). In this study, we sought to examine the efficacy of using the VTIQ technique as a method for differentiating between injured and non-affected ATFLs from the viewpoint of tissue stiffness. In this study, patients with ATFL type I injury were selected as research subjects, and differences between injured and non-affected ATFL stiffness at different injury phases were specifically analyzed.

\section{Methods}

\section{Patients}

The study was conducted following the Declaration of Helsinki (as revised in 2013). The Medical Ethics Committee approved this study of The Second Affiliated Hospital of Wenzhou Medical University (approval number: 2019-03), and individual consent for this retrospective analysis was waived. We retrospectively reviewed patients who visited our hospital from October 2018 to October 2020 and identified patients who had undergone ankle ultrasonography and magnetic resonance imaging (MRI) at the time of their visit. Patients' medical records and imaging data were retrieved from the hospital database server using the search term "ATFL type I injury".

To be eligible to participate in the study, patients had to meet the following inclusion criteria: (I) have ankle ultrasonography and MRI results showing a unilateral ATFL type I injury. An ATFL presented with stretching and interstitial tearing on MRI was classified as a type I injury (21). An experienced musculoskeletal radiologist made the MRI interpretations and diagnoses; (II) have failed to seek medical attention or accept treatment promptly. Conversely, patients were excluded from the study if they met any of the following exclusion criteria: (I) had a systemic disease that had an impact on the physiological characteristics of the ligament, including rheumatoid arthritis, systemic lupus erythematosus, diabetes mellitus, or gouty arthritis; (II) had a neuromuscular disease, including peripheral neuropathy, syringomyelia, or amyotrophic lateral sclerosis; and/or (III) had incomplete clinical data.

In total, 206 patients were reviewed retrospectively in the study (Table 1). The patients were categorized into one of the 3 following groups based on the time since the last ankle sprain: (I) the acute injury group, within 3 days (median time: 2 days) (81 cases); (II) the subacute injury group, between 3 and 30 days (median time: 19 days) (69 cases); and (III) the chronic injury group, more than 30 days (median time: 120 days) (56 cases).

\section{Ultrasound examination procedure}

An ankle ultrasound examination was performed using ACUSON Oxana2 ultrasonic diagnostic apparatus (Siemens Medical Solutions USA, Inc. 685 East Middlefield Road. Mountain View, CA 94043, USA) equipped with a VTIQ mode and a 9L4 linear array transducer (7-9 MHz).

During the examinations, each patient was instructed to 
Table 1 Characteristics of acute, subacute, and chronic ATFL type I injury cases

\begin{tabular}{|c|c|c|c|c|}
\hline Variable & $\begin{array}{l}\text { Acute ATFL injury } \\
\text { group }(n=81)\end{array}$ & $\begin{array}{c}\text { Subacute ATFL injury } \\
\text { group }(n=69)\end{array}$ & $\begin{array}{l}\text { Chronic ATFL injury } \\
\text { group }(n=56)\end{array}$ & $\begin{array}{l}\text { Statistical } \\
\text { significance }\end{array}$ \\
\hline Injured side (left/right) & $36 / 45$ & $27 / 42$ & $31 / 25$ & $P=0.187$ \\
\hline Age (years) & $32.88 \pm 11.11$ & $33.08 \pm 10.86$ & $33.14 \pm 10.95$ & $P=0.995$ \\
\hline SWV of the non-affected ATFL $(\mathrm{m} / \mathrm{s})$ & $7.50 \pm 1.12(7.59)$ & $7.53 \pm 1.06(7.41)$ & $7.61 \pm 1.30(7.67)$ & $P=0.850$ \\
\hline
\end{tabular}

Injured side and sex are presented as numbers. SWV is presented as mean \pm standard deviation (median). Other data are expressed as mean \pm standard deviation. ATFL, anterior talofibular ligament; BMI, body mass index; SWV, shear wave velocity.

rest on the flat surface of the examination table in a seated position and flex their hip to 45 degrees and their knee to 90 degrees to produce an ankle internal rotation of about 25 degrees (22) (Figure 1A). In this ankle position, the ATFL was stretched moderately to observe its continuity and echogenicity better. The ultrasound probe was placed on the surface of the lateral malleolus, with one end on the fibular malleolus and the other end on the talus (Figure 1B). The probe was adjusted to ensure it was as parallel as possible to the long axis of the ATFL. During the VTIQ imaging, considerable care was taken to avoid applying pressure to the ligament. Following image stabilization, a shear wave velocity (SWV) measurement was taken using a region of interest (ROI) of $1 \mathrm{~mm} \times 1 \mathrm{~mm}$. The ROI was placed in the central region of the ATFL (Figure 1C). 3 ROIs were sampled per image. For each ATFL, 6 different images were acquired. The average value was selected for statistical analysis. An experienced musculoskeletal ultrasonography technician took all the ATFL SWV measurements.

\section{Statistical analysis}

Before statistical testing, a Shapiro-Wilk test was performed to test the variables for normality. Continuous values with normal distribution were presented as mean \pm standard deviation (SD). We compared the SWV values of the injured ATFLs among the acute, subacute, and chronic groups and the non-affected ATFLs, using a one-way analysis of variance followed by a Fisher's least significant difference (LSD) post-hoc test. Next, the SWV values of the injured ATFLs were compared to those of the non-affected ATFLs in each group using an independent samples $t$-test. The validity of the ATFL SWV in the diagnosis of ATFL type I injury was estimated by the receiver operator characteristics (ROC) curve, cut-off values, sensitivity, specificity, and area under the curve (AUC) with a $95 \%$ confidence interval (CI). The categorical data were compared using a Chisquare test. A P value less than 0.05 indicated a statistically significant difference. All the above-mentioned statistical analyses were performed using SPSS (IBM, Chicago, IL, USA), version 22.0. The power calculation was performed using PASS (NCSS, LLC. Kaysville, Utah, USA) version 15.0.5.

\section{Results}

The average SWV of the injured ATFL was $4.09 \pm 1.15 \mathrm{~m} / \mathrm{s}$ in the acute ATFL injury group, $5.60 \pm 1.39 \mathrm{~m} / \mathrm{s}$ in the subacute ATFL injury group, and $7.74 \pm 1.44 \mathrm{~m} / \mathrm{s}$ in the chronic ATFL injury group $(\mathrm{F}=132.237 ; \mathrm{P}<0.001$; Power $=100.00 \%)$. The acute injury group had significantly lower ATFL SWV than the subacute injury group (LSD- $t$ $=-6.726 ; \mathrm{P}<0.001)$ and the chronic injury group $(\mathrm{LSD}-\mathrm{t}$ $=-16.260 ; \mathrm{P}<0.001)$. The ATFL SWV of the subacute injury group was significantly lower than that of the chronic injury group $(\mathrm{LSD}-\mathrm{t}=-8.919 ; \mathrm{P}<0.001)$ (Figure 2$)$. There were no significant differences in the SWV values of the nonaffected ATFLs among the acute, subacute, and chronic ATFL injury groups $(\mathrm{F}=0.162 ; \mathrm{P}=0.850$; Power $=7.33 \%)$. The average SWV of the injured ATFL was significantly lower than that of the non-affected ATFL in the acute ATFL injury group $(4.09 \pm 1.15$ vs. $7.50 \pm 1.12 \mathrm{~m} / \mathrm{s} ; \mathrm{t}=-18.997$; $\mathrm{P}<0.001$; Power $=100.00 \%)$. Similarly, the average SWV of the injured ATFL was significantly lower than that of the non-affected ATFL in the subacute ATFL injury group $(5.60 \pm 1.39$ vs. $7.53 \pm 1.06 \mathrm{~m} / \mathrm{s} ; \mathrm{t}=-8.557, \mathrm{P}<0.001$; Power 

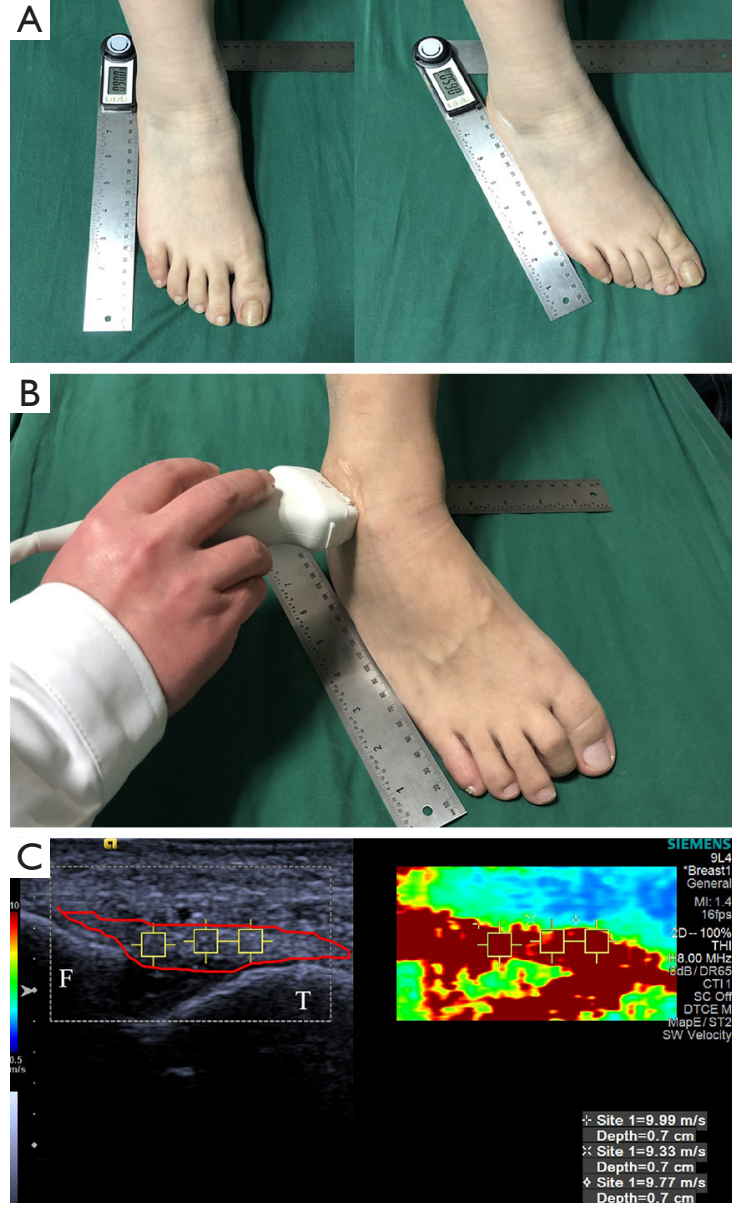

Figure 1 Patient position during the examination and the schematic diagram for ATFL SWV measurement using the VTIQ technique. (A) Patients were instructed to flex the feet internal rotation to 25 degrees. Angles were measured using a ruler. (B) An ultrasound probe was placed on the surface of the lateral malleolus, with one end on the fibular malleolus and the other on the talus. (C) SWV of ATFL was measured using the VTIQ technique with an ROI of $1 \mathrm{~mm} \times 1 \mathrm{~mm}$. The ROI was placed in the central region of ATFL. Red lines mark the outline of the ATFL. T: tibia; F: fibula. ATFL, anterior talofibular ligament; SWV, shear wave velocity; VTIQ, virtual touch tissue imaging quantification; ROI, region of interest.

$=100.00 \%)$. However, for the chronic ATFL injury group, there was no significant difference in the SWV values between injured and non-affected ATFLs $(7.74 \pm 1.44 v s$. $7.61 \pm 1.30 \mathrm{~m} / \mathrm{s} ; \mathrm{t}=0.522 ; \mathrm{P}=0.603$; Power $=12.59 \%$ ).

Concerning the validity of the ATFL SWV as a predictor of acute and subacute ATFL type I injury, the ROC curve analysis showed that the best cut-off point for the SWV was
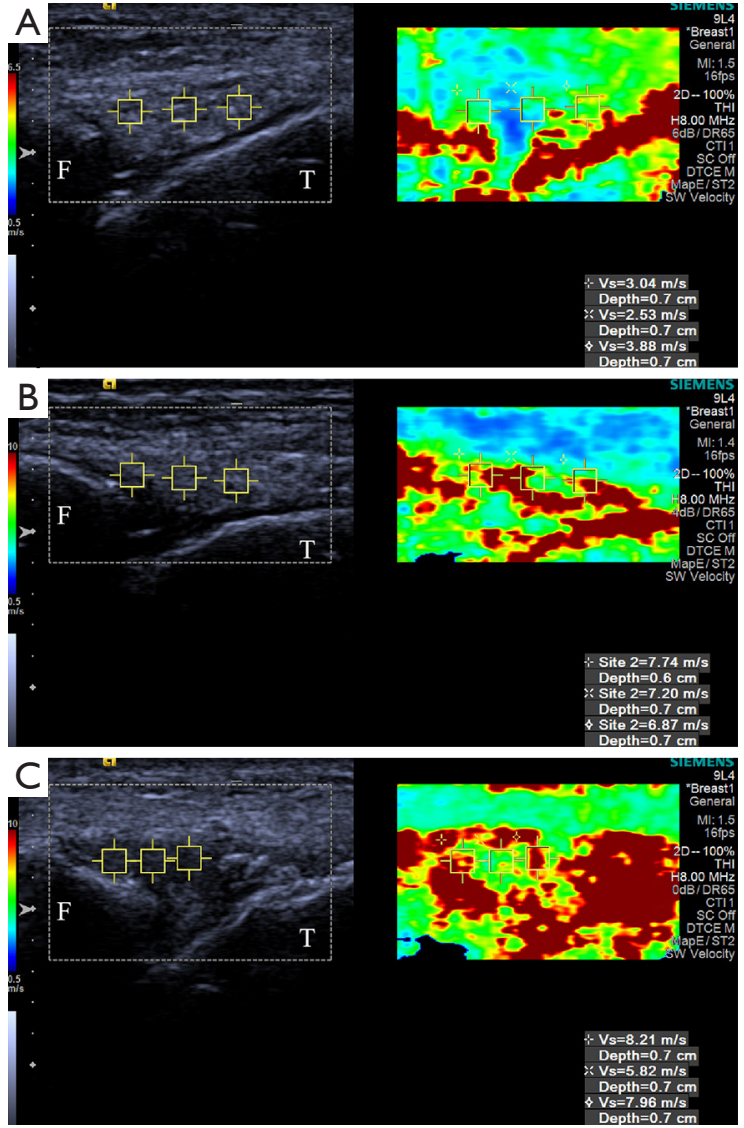

Figure 2 Injured ATFL in each group. ATFL SWV was measured using the VTIQ technique. (A) Injured ATFL in the acute group; the measured SWV was $2.53-3.88 \mathrm{~m} / \mathrm{s}$. (B) Injured ATFL in the subacute group; the measured SWV was $6.87-7.74 \mathrm{~m} / \mathrm{s}$. (C) Injured ATFL in the chronic group; the measured SWV was $5.82-8.21 \mathrm{~m} / \mathrm{s}$. T: tibia; F: fibula. ATFL, anterior talofibular ligament; SWV, shear wave velocity; VTIQ, virtual touch tissue imaging quantification.

$6.165 \mathrm{~m} / \mathrm{s}$, with $84.3 \%$ sensitivity, $88.5 \%$ specificity, and an AUC of 0.93 (95\% CI, 0.90-0.95) (Figure 3).

\section{Discussion}

The ATFL, the calcaneofibular ligament, and the posterior talofibular ligament form the lateral ankle ligament complex. It is a flat, quadrilateral ligament composed of 2 or 3 bands or may be fasciculated (23). Compared with the other 2 ligaments, the structure of the ATFL is relatively weak (4). The ATFL extends from the anterior margin of the fibular malleolus, running forward and medially, forms a tent-like structure over the talus, and then attaches to the front of the lateral articular facet and the neck of the 


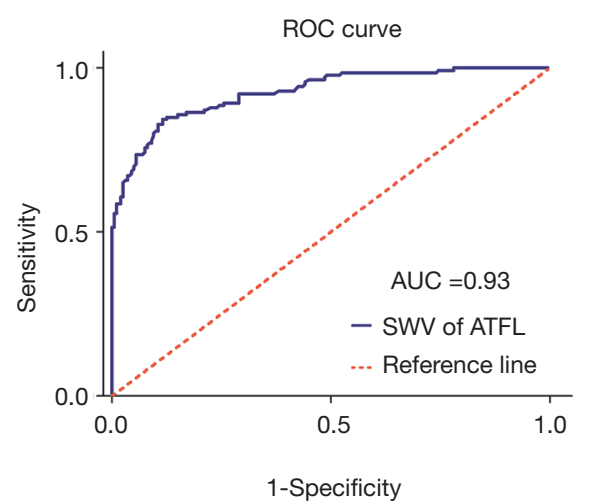

Figure 3 The ROC curve of ATFL SWV for detecting acute and subacute ATFL type I injury with sensitivity as the vertical coordinate and 1-specificity as the horizontal coordinate. The best cut-off point for SWV was $6.165 \mathrm{~m} / \mathrm{s}$, with $84.3 \%$ sensitivity, $88.5 \%$ specificity, and an AUC of 0.93 (95\% CI, 0.90-0.95). ROC, receiver operator characteristics; ATFL, anterior talofibular ligament; SWV, shear wave velocity; AUC, area under the curve; CI, confidence interval.

talus (24). Due to its structure and attachment position, the ATFL plays an important role in restricting the internal rotation of the talus (25). However, at the same time, the ATFL is vulnerable to injury in excessive ankle joint varus (26). An abnormal ATFL is thought to contribute to ligament laxity and CAI (7). Thus, it is necessary to evaluate the ATFL in patients with an ankle sprain. An accurate and timely diagnosis could provide a good foundation for a patient's future treatment.

Currently, many diagnostic methods are available for detecting ATFL injury. Several of these methods, including stress radiography, MRI, ultrasonography, arthrography, and arthroscopy, are quite mature and have already been widely used in clinical practice $(27,28)$. The majority of these methods focus on the external morphological changes of the injured ATFL. However, some of the methods have limitations. For example, while arthroscopy is used as the reference standard, it is invasive and operator-dependent (29), and while MRI has high specificity for diagnosing ATFL injury, its requirements for body position are relatively strict (30). Thus, we decided to examine the injury from the perspective of tissue changes inside an injured ligament. The VTIQ technique was applied in this study, which allows for quantitative measurements of tissue stiffness in a non-invasive manner.

To date, very few studies appear to have been conducted on ATFL stiffness. Hotfiel et al. (31) assessed ATFL stiffness in healthy athletes using a virtual touch tissue quantification (VTQ) technique and found that the average ATFL SWV was about $1.79 \pm 0.20 \mathrm{~m} / \mathrm{s}$ for all participants, $1.72 \pm 0.36 \mathrm{~m} /$ $\mathrm{s}$ for females, and $1.85 \pm 0.31 \mathrm{~m} / \mathrm{s}$ for males (31). Conversely, this work showed that the average SWV of the non-affected ATFL was $7.50 \pm 1.12 \mathrm{~m} / \mathrm{s}$ in the acute group, $7.53 \pm 1.06 \mathrm{~m} /$ $\mathrm{s}$ in the subacute group, and $7.61 \pm 1.30 \mathrm{~m} / \mathrm{s}$ in the chronic group. There could be several reasons for the differences between the present study results and those of Hotfiel et al. First, and presumably, the most important, the differences may be related to the different techniques used in each study. VTQ has a fixed-size ROI of $6 \mathrm{~mm} \times 5 \mathrm{~mm}$, which may be too large for ATFL measurements. The surrounding soft tissues of the ATFL within the ROI might obscure the stiffness of the ligament, resulting in an underestimate of the SWV value of the ATFL.

Conversely, VTIQ has a manually adjustable ROI, whose minimum achievable size is $1 \mathrm{~mm} \times 1 \mathrm{~mm}$; thus, it is especially accurate for small structures and allows for targeted multi-point measurements. Additionally, the results obtained using the VTIQ technique may be more reflective of actual ATFL stiffness. Second, the range of measurement of the VTIQ $(0.5-10 \mathrm{~m} / \mathrm{s})$ is broader than that of the VTQ, which ensures that the SWV value in the ROI is not too high to be measured (32). Third, different ankle positions may also affect the results. In Hotfiel et al.'s study, the patient's ankle was placed in a neutral position, while in the present study, the internal rotation of the ankle joint was performed. Compared to the neutral position, additional stretch stress is loaded onto the ATFL in the stretch position, and this stress could cause some changes in ATFL stiffness.

In the present study, the acute injury group had a significantly lower ATFL SWV $(4.09 \pm 1.15 \mathrm{~m} / \mathrm{s})$ than that of the subacute injury group $(5.60 \pm 1.39 \mathrm{~m} / \mathrm{s})$ and the chronic injury group $(7.74 \pm 1.44 \mathrm{~m} / \mathrm{s})$. The ATFL SWV in the subacute injury group was significantly lower than that of the chronic injury group. These results indicate that the stiffness of injured ATFLs varies at different stages. The varied stiffness of the ligament observed in this study may be associated with pathological changes in different disease courses. Following an acute trauma, the inflammatory process sets in, and a variety of inflammatory mediators are released at the injured site, resulting in ankle pain and swelling (33). These acute-phase responses will be weaker in the subacute phase and gradually subside in the chronic phase in the absence of a new-onset trauma. Given this, we 
suggest that ligament stiffness can be accurately evaluated using the VTIQ technique, which could in part reflect the pathological condition of the injured ATFL.

In addition, our study showed that injured ATFLs had significantly lower SWV values than those of non-affected ATFLs in the acute and subacute groups; however, no significant difference was found for the chronic group. Our view that the stiffness differences between the injured and non-affected ATFLs are associated with pathological changes in the ligament after injury. This finding supports a similar trend found in previous studies. Notably, Rosskopf et al. (34) found that the mean total SWV of the supraspinatus muscle in patients with the symptomatic shoulder was lower than that in healthy volunteers. Hou et al. (35) found that the SWV of the deltoid muscle was lower in painful shoulders than in asymptomatic shoulders. VTIQ can identify the stiffness differences between injured and non-affected ATFLs in the acute and subacute phases. Concerning a chronic injury, possibly because of the subsidence of tissue edema, the injured ligament tissue gradually recovers to the original dense state.

Consequently, the stiffness difference between injured and non-affected ATFLs cannot be assessed using the VTIQ technique. Further, it is also possible that stiffness differences between injured and non-affected ATFLs in the chronic group do exist. However, due to the small sample size, the power may have been too low to detect this difference in the present study. In this respect, we believe that before drawing a reliable conclusion for the chronic ATFL type I injury, studies with a larger sample size need to be conducted in the future. However, taken together, our results suggest that VTIQ can be used to identify acute and subacute ATFL type I injury.

This study also tested the validity of the ATFL SWV as a predictor of acute and subacute ATFL type I injury. The results obtained from ROC analysis showed that ATFL SWV had high sensitivity and specificity, which further indicates that the VTIQ technique is a reliable method for diagnosing ATFL injury.

The current study had several limitations. First, it was a single-center study, and the case numbers were relatively small, especially those for the chronic ATFL type I injury cases. More patients need to be included in future research. Second, as this study undertook a retrospective analysis and one examiner collected the data, we could not calculate the inter-observer variability. Third, the effect of the ankle position on the VTIQ results was unable to be assessed. Future prospective studies need to provide a more comprehensive and reliable basis for the application of VTIQ.

\section{Conclusions}

In conclusion, the VTIQ technique can be used as an additional diagnostic tool for identifying acute and subacute ATFL type I injury and represents a new approach for tracking the development of a ligament injury. However, further research needs to be undertaken on chronic ATFL type I injury.

\section{Acknowledgments}

We would like to thank Yi Lu for his technical help. Funding: None.

\section{Footnote}

Conflicts of Interest: All the authors have completed the ICMJE uniform disclosure form (available at http://dx.doi. org/10.21037/qims-21-203). The authors have no conflicts of interest to declare.

Ethical Statement: The authors are accountable for all aspects of the work, including ensuring that questions related to the accuracy or integrity of any part of the work have been appropriately investigated and resolved. The study was conducted following the Declaration of Helsinki (as revised in 2013). The Medical Ethics Committee approved this study of The Second Affiliated Hospital of Wenzhou Medical University (approval number: 2019-03), and individual consent for this retrospective analysis was waived.

Open Access Statement: This is an Open Access article distributed in accordance with the Creative Commons Attribution-NonCommercial-NoDerivs 4.0 International License (CC BY-NC-ND 4.0), which permits the noncommercial replication and distribution of the article with the strict proviso that no changes or edits are made and the original work is properly cited (including links to both the formal publication through the relevant DOI and the license). See: https://creativecommons.org/licenses/by-nc-nd/4.0/.

\section{References}

1. Waterman BR, Owens BD, Davey S, Zacchilli MA, 
Belmont PJ. The Epidemiology of Ankle Sprains in the United States. J Bone Joint Surg Am 2010;92:2279-84.

2. Doherty C, Delahunt E, Caulfield B, Hertel J, Ryan J, Bleakley C. The Incidence and Prevalence of Ankle Sprain Injury: A Systematic Review and Meta-Analysis of Prospective Epidemiological Studies. Sports Med 2014;44:123-40.

3. Roos KG, Kerr ZY, Mauntel TC, Djoko A, Dompier TP, Wikstrom EA. The Epidemiology of Lateral Ligament Complex Ankle Sprains in National Collegiate Athletic Association Sports. Am J Sports Med 2017;45:201-9.

4. Martin RL, Davenport TE, Paulseth S, Wukich DK, Godges JJ. Ankle Stability and Movement Coordination Impairments: Ankle Ligament Sprains Clinical Practice Guidelines Linked to the International Classification of Functioning, Disability and Health From the Orthopaedic Section of the American Physical Therapy Association. J Orthop Sports Phys Ther 2013;43:A1-40.

5. Thompson C, Schabrun S, Romero R, Bialocerkowski A, van Dieen J, Marshall P. Factors Contributing to Chronic Ankle Instability: A Systematic Review and Meta-Analysis of Systematic Reviews. Sports Med 2018;48:189-205.

6. Vuurberg G, Hoorntje A, Wink LM, van der Doelen BFW, van den Bekerom MP, Dekker R, van Dijk CN, Krips R, Loogman MCM, Ridderikhof ML, Smithuis FF, Stufkens SAS, Verhagen EALM, de Bie RA, Kerkhoffs GMMJ. Diagnosis, treatment and prevention of ankle sprains: update of an evidence-based clinical guideline. $\mathrm{Br}$ J Sports Med 2018;52:956.

7. Johnson EE, Markolf KL. The contribution of the anterior talofibular ligament to ankle laxity. J Bone Joint Surg Am 1983;65:81-8.

8. Shoji H, Teramoto A, Sakakibara Y, Kamiya T, Watanabe K, Fujie H, Yamashita T. Kinematics and Laxity of the Ankle Joint in Anatomic and Nonanatomic Anterior Talofibular Ligament Repair: A Biomechanical Cadaveric Study. Am J Sports Med 2019;47:667-73.

9. van Rijn RM, van Os AG, Bernsen RMD, Luijsterburg PA, Koes BW, Bierma-Zeinstra SMA. What is the clinical course of acute ankle sprains? A systematic literature review. Am J Med 2008;121:324-31.e6.

10. Doherty C, Bleakley C, Hertel J, Caulfield B, Ryan J, Delahunt E. Recovery From a First-Time Lateral Ankle Sprain and the Predictors of Chronic Ankle Instability: A Prospective Cohort Analysis. Am J Sports Med 2016;44:995-1003.

11. Gribble PA, Bleakley CM, Caulfield BM, Docherty CL, Fourchet F, Fong DTP, Hertel J, Hiller CE, Kaminski
TW, McKeon PO, Refshauge KM, Verhagen EA, Vicenzino BT, Wikstrom EA, Delahunt E. 2016 consensus statement of the International Ankle Consortium: prevalence, impact and long-term consequences of lateral ankle sprains. Br J Sports Med 2016;50:1493-5.

12. Golditz T, Steib S, Pfeifer K, Uder M, Gelse K, Janka R, Hennig FF, Welsch GH. Functional ankle instability as a risk factor for osteoarthritis: using T2-mapping to analyze early cartilage degeneration in the ankle joint of young athletes. Osteoarthritis Cartilage 2014;22:1377-85.

13. Lee SH, Yun SJ. The feasibility of point-of-care ankle ultrasound examination in patients with recurrent ankle sprain and chronic ankle instability: Comparison with magnetic resonance imaging. Injury 2017;48:2323-8.

14. Abdeen R, Comfort P, Starbuck C, Nester C. Ultrasound Characteristics of Foot and Ankle Structures in Healthy, Coper, and Chronically Unstable Ankles. J Ultrasound Med 2019;38:917-26.

15. Seok H, Lee SH, Yun SJ. Diagnostic performance of ankle ultrasound for diagnosing anterior talofibular and calcaneofibular ligament injuries: a meta-analysis. Acta Radiol 2020;61:651-61.

16. Mun JU, Cho HR, Sung YJ, Kang KN, Lee J, Joo Y, Kim $\mathrm{YU}$. The role of the anterior talofibular ligament area as a morphological parameter of the chronic ankle sprain. J Orthop Sci 2020;25:297-302.

17. Santiago T, Alcacer-Pitarch B, Salvador MJ, Del Galdo F, Redmond AC, da Silva JA. A preliminary study using virtual touch imaging and quantification for the assessment of skin stiffness in systemic sclerosis. Clin Exp Rheumatol 2016;34:137-41.

18. Fu S, Cui L, He X, Sun Y. Elastic Characteristics of the Normal Achilles Tendon Assessed by Virtual Touch Imaging Quantification Shear Wave Elastography. J Ultrasound Med 2016;35:1881-7.

19. Karatekin YS, Karaismailoglu B, Kaynak G, Ogut T, Dikici AS, Esmerer EU, Aydingoz O, Botanlioglu H. Does elasticity of Achilles tendon change after suture applications? Evaluation of repair area by acoustic radiation force impulse elastography. J Orthop Surg Res 2018;13:45.

20. Zhang C, Li M, Jiang J, Zhou Q, Xiang L, Huang Y, Ban W, Peng W. Diagnostic Value of Virtual Touch Tissue Imaging Quantification for Evaluating Median Nerve Stiffness in Carpal Tunnel Syndrome. J Ultrasound Med 2017;36:1783-91.

21. Kreitner KF, Ferber A, Grebe P, Runkel M, Berger S, Thelen M. Injuries of the lateral collateral ligaments 
of the ankle: assessment with MR imaging. Eur Radiol 1999;9:519-24.

22. Croy T, Saliba S, Saliba E, Anderson MW, Hertel J. Talofibular Interval Changes After Acute Ankle Sprain: A Stress Ultrasonography Study of Ankle Laxity. J Sport Rehabil 2013;22:257-63.

23. Yildiz S, Yalcin B. The anterior talofibular and calcaneofibular ligaments: an anatomic study. Surg Radiol Anat 2013;35:511-6.

24. Khawaji B, Soames R. The anterior talofibular ligament: A detailed morphological study. Foot (Edinb) 2015;25:141-7.

25. Rasmussen O. Stability of the ankle joint. Analysis of the function and traumatology of the ankle ligaments. Acta Orthop Scand Suppl 1985;211:1-75.

26. Golanó P, Vega J, de Leeuw PA, Malagelada F, Manzanares MC, Götzens V, van Dijk CN. Anatomy of the ankle ligaments: a pictorial essay. Knee Surg Sports Traumatol Arthrosc 2016;24:944-56.

27. Cho JH, Lee DH, Song HK, Bang JY, Lee KT, Park YU. Value of stress ultrasound for the diagnosis of chronic ankle instability compared to manual anterior drawer test, stress radiography, magnetic resonance imaging, and arthroscopy. Knee Surg Sports Traumatol Arthrosc 2016;24:1022-8.

28. Staats K, Sabeti-Aschraf M, Apprich S, Platzgummer H, Puchner SE, Holinka J, Windhager R, Schuh R. Preoperative MRI is helpful but not sufficient to detect associated lesions in patients with chronic ankle instability. Knee Surg Sports Traumatol Arthrosc 2018;26:2103-9.

29. Ferkel RD, Small HN, Gittins JE. Complications in

Cite this article as: Chen X, Wang L, Li X, Fu P, Xu M, Zou C, Li X, Dong Y. Can virtual touch tissue imaging quantification be a reliable method to detect anterior talofibular ligament type I injury at the acute, subacute, and chronic stages? Quant Imaging Med Surg 2021;11(10):4334-4341. doi: 10.21037/ qims-21-203 foot and ankle arthroscopy. Clin Orthop Relat Res 2001;391:89-104.

30. Jung HG, Kim NR, Kim TH, Eom JS, Lee DO. Magnetic Resonance Imaging and Stress Radiography in Chronic Lateral Ankle Instability. Foot Ankle Int 2017;38:621-6.

31. Hotfiel T, Heiss R, Janka R, Forst R, Raithel M, Lutter C, Gelse K, Pachowsky M, Golditz T. Acoustic radiation force impulse tissue characterization of the anterior talofibular ligament: a promising noninvasive approach in ankle imaging. Phys Sportsmed 2018;46:435-40.

32. Yang YP, Xu XH, Bo XW, Liu BJ, Guo LH, Xu JM, Sun LP, Xu HX. Comparison of Virtual Touch Tissue Imaging \& Quantification (VTIQ) and Virtual Touch Tissue Quantification (VTQ) for diagnosis of thyroid nodules. Clin Hemorheol Microcirc 2017;65:137-49.

33. Kaminski TW, Hertel J, Amendola N, Docherty CL, Dolan MG, Hopkins JT, Nussbaum E, Poppy W, Richie D. National Athletic Trainers' Association Position Statement: Conservative Management and Prevention of Ankle Sprains in Athletes. J Athl Train 2013;48:528-45.

34. Rosskopf AB, Ehrmann C, Buck FM, Gerber C, Fluck M, Pfirrmann CWA. Quantitative Shear-Wave US Elastography of the Supraspinatus Muscle: Reliability of the Method and Relation to Tendon Integrity and Muscle Quality. Radiology 2016;278:465-74.

35. Hou SW, Merkle AN, Babb JS, McCabe R, Gyftopoulos S, Adler RS. Shear Wave Ultrasound Elastographic Evaluation of the Rotator Cuff Tendon. J Ultrasound Med 2017;36:95-106. 